\title{
LIFE SCIENCE APPLICATIONS UTILIZING RADIOCARBON TRACING
}

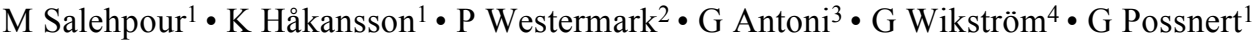

ABSTRACT. Radiocarbon-based accelerator mass spectrometry (AMS) facilities at Uppsala University include a measurement center for archaeological applications and a separate entity dedicated to life science research. This paper addresses the latter, with the intention of giving a brief description of the biomedical activities at our laboratory, as well as presenting new data. The ultra-small sample preparation method, which can be used down to a few $\mu \mathrm{g} \mathrm{C}$ samples, is outlined and complemented with new results. Furthermore, it is shown that the average secondary ion current performance for small samples can be improved by increasing the distance between the cathode surface and the pressed graphite surface. Finally, data is presented for a new application: Amyloidoses are a group of diseases where the conformational changes in specific proteins' structure lead to the formation of extracellular deposits that spread and increase in mass and eventually may lead to total organ failure and death. The formation timeframe is unknown and yet it is an important clue for the elucidation of the mechanism. We present results on bomb-peak dating of 4 different types of purified amyloid proteins from human postmortem heart and spleen samples. The data indicates that the average measured age of the carbon originating from the systemic amyloid types studied here correspond to a few years before the death of the subject. This suggests that a major part of the fibril formation takes place during the last few years before death, rather than as an accumulation of amyloid deposits over decades.

\section{INTRODUCTION}

Since the introduction of biomedical applications of accelerator mass spectrometry (AMS) over 2 decades ago (Turteltaub et al. 1990), a number of new applications have been introduced using a variety of rare isotopes. Due to the organic nature of living organisms, the radiocarbon-based applications have consistently been the most predominant type of biomedical AMS. Some applications have been commercially successful, such as the microdosing concept (Lappin and Garner 2003) addressing the pharmaceutical industry. The method facilitates administration of small, subpharmacological (micro-) doses of ${ }^{14} \mathrm{C}$-labeled drug candidates directly to humans, minimizing toxicity issues and yet providing pharmacokinetic data, i.e. how the drug is absorbed, distributed, metabolized, and excreted in the human body. This line of research is pursued at our laboratory with routine studies as well as contributions to specialized fields such as drug transport mechanism studies of the blood-brain barrier (Sadiq et al. 2011) as well as studies of macromolecules (Salehpour et al. 2011).

Other applications provide fundamental data pertaining to human physiology and cell biology. Examples of the latter are bomb-peak dating of postmortem human DNA, providing sought-after information on whether specific human cells regenerate. The concept behind this type of research is that the time dependence of the ${ }^{14} \mathrm{C}$ level in the atmospheric $\mathrm{CO}_{2}$ is well documented (CALIBomb, http://calib.qub.ac.uk/CALIBomb/frameset.html), reflecting the elevated ${ }^{14} \mathrm{C}$ levels due to nuclear weapons tests during the Cold War, and the subsequent decrease after the Limited Test Ban Treaty (prohibiting all test detonations of nuclear weapons except underground). The ${ }^{14} \mathrm{C}$ levels are inscribed in the DNA during the cell division process, using atmospheric carbon that entered the food cycle through photosynthesis in plants. For cells that do not regenerate, the ${ }^{14} \mathrm{C}$ level in the DNA will reflect the corresponding ${ }^{14} \mathrm{C}$ level in the atmosphere at the time of birth. Many cells, however, do regenerate and, moreover, mathematical models can be used to extract the regeneration

\footnotetext{
${ }^{1}$ Department of Physics and Astronomy, Applied Nuclear Physics Division, Ion Physics, PO Box 516, SE-751 20 Uppsala, Sweden. Corresponding author: mehran.salehpour@physics.uu.se.

${ }^{2}$ Department of Immunology, Genetics and Pathology, Molecular and Morphological Pathology, Rudbeck Laboratory, Uppsala University, SE-751 85 Uppsala, Sweden.

${ }^{3}$ PET-Centre, Centre for Medical Imaging, Uppsala University Hospital, SE-751 85 Uppsala, Sweden.

${ }^{4}$ Department of Medical Sciences, Cardiology, Uppsala University Hospital, SE-751 85 Uppsala, Sweden.
}

C 2013 by the Arizona Board of Regents on behalf of the University of Arizona

Proceedings of the 21st International Radiocarbon Conference edited by A J T Jull \& C Hatté

RADIOCARBON, Vol 55, Nr 2-3, 2013, p 865-873 


\section{Salehpour et al.}

rate (Bernard et al. 2010). Examples of published data are the human brain hippocampus (Spalding 2013), the human cardimyocytes in the heart (Bergmann et al. 2009), and the human fat cells, adipocytes (Spalding et al. 2008). Also, a variety of tissues can be studied such as triglycerides from human fat tissues (Arner et al. 2011) or the plaque from human carotid arteries (Hägg et al. 2011). There are also forensic applications, such as the determination of the date of birth using bomb-peak dating of teeth (Spalding et al. 2005; Alkass et al. 2009).

There are over 200 different types of cells in the human body, many with unknown regeneration rates. With this in mind, in collaboration with the Karolinska Institute in Stockholm, we founded The Human Regeneration Map Project (THRM, www.thrm.ki.se). THRM is a 10-yr project with the purpose of measuring the regeneration of the various human cells, not only in health but also in combination with various diseases.

For a number of applications, the availability of sample substance is limited, establishing the need for analysis of small samples. In this paper, a brief description of the ultra-small sample preparation utilized in our laboratory method is given, followed by some new data concerning the optimization of the method. In the next section, data are provided for a new application involving bomb-peak dating of postmortem amyloid plaques.

\section{THE AMS FACILITY AT UPPSALA UNIVERSITY}

The AMS setup in Uppsala is currently based on a 5MV Pelletron tandem accelerator (NEC Inc., Middleton, Wisconsin, USA) which has been in operation since 2001. The accelerator is injected with 4 ion sources: 2 of which are used for AMS, 1 for labeled substances ( $>2$ Modern), and the other for low-activity samples such as archaeological or bomb-peak dating samples. Three sample preparation laboratories operate in parallel, 1 exclusively for archaeological samples and 2 for biomedical applications. Two stable isotope ratio mass spectrometers (IRMS) are also in operation. In an effort to expand the capacity and comply with the state-of-the-art instrumentation, a new AMS machine will be delivered in the spring of 2014. The system is a MICADAS developed and manufactured by ETH Zurich, Switzerland (Synal et al. 2007).

\section{Ultra-Small Samples}

In many applications, the amount of sample available for analysis is limited. Furthermore, as AMS is a destructive method, it further restricts the applicability of this method for irreplaceable samples. Consequently, small-sample AMS, offering analysis in the few $\mu \mathrm{g} C$ range, is of considerable interest.

The standard sample preparation method used here has been published earlier (Salehpour et al. 2008, 2009), which pertains to large samples in the $1 \mathrm{mg} \mathrm{C}$ range. The ultra-small sample (USS) method addresses sample sizes from about $500 \mu \mathrm{g} \mathrm{C}$ down to a few $\mu \mathrm{g} \mathrm{C}$ and has also been described in detail in Salehpour et al. (2013). Thus, only a brief description is given here.

Depending on the mass of the sample, $10-20 \mathrm{mg}$ of pretreated $\mathrm{CuO}$ powder is added to the sample in a prebaked quartz tube and is baked in a muffle furnace at $950{ }^{\circ} \mathrm{C}$ for about $3 \mathrm{hr}$. After cooling, the quartz tube is cracked and the gas is introduced into a vacuum line. The gas then undergoes a purification step, by freezing out the water content in a cold trap $\left(-80^{\circ} \mathrm{C}\right)$ and pumping away the residual gases. The amount of $\mathrm{CO}_{2}$ gas is measured using a calibrated volume and a pressure transducer. The gas subsequently is moved cryogenically and deposited in a graphitization reactor, which is a sub-mL, prebaked borosilicate tube containing $10 \mathrm{mg}$ zinc powder at the bottom and a smaller vial placed within, containing iron powder $(2 \mathrm{mg})$. The tube is then sealed and baked at $550{ }^{\circ} \mathrm{C}$ for $6 \mathrm{hr}$. Unlike the large samples ( $>50 \mu \mathrm{g} \mathrm{C})$, where the graphite can easily be seen, samples in the 10- 
$\mu \mathrm{g} C$ range are not seen directly and only show a change of color in the iron catalyst. Throughout the process, extreme care needs to be taken to avoid introduction of stray carbon into the sample. The method has been shown to be highly reliable, with high graphitization yield and showing very low fractionations $(<0.1 \%$ for samples below $500 \mu \mathrm{g} \mathrm{C})$.

One important quantity in AMS measurement is the secondary ion current obtained from the sample. For a given analysis time, the higher the current, the better is the statistical ensemble and hence the precision. There is a dependence of the extracted ion current on the mass of the sample as can be seen in Figure 1. The data contains over 3600 data points for samples prepared using the USS preparation method, updated since the last report (Salehpour et al. 2013). No data points have been excluded even though a few samples should have been rejected as outliers due to low current. This is to present the total scatter in the measurement that has been recorded so far. The updated data are consistent with our previous data containing 1329 points (Salehpour et al. 2013). It is noted that the current is more or less constant for mg samples down to about 100- $\mu \mathrm{g} \mathrm{C}$ samples. Below this value, the current is linearly dependent on the mass of the sample. As the precision is dependent on current (proportional to the square root of the current), this implies that small samples inherently give rise to lower precisions. As an example, a 10- $\mu \mathrm{g} \mathrm{C}$ sample provides 10 times lower current compared to a 1-mg sample and consequently has about 3 times lower precision.

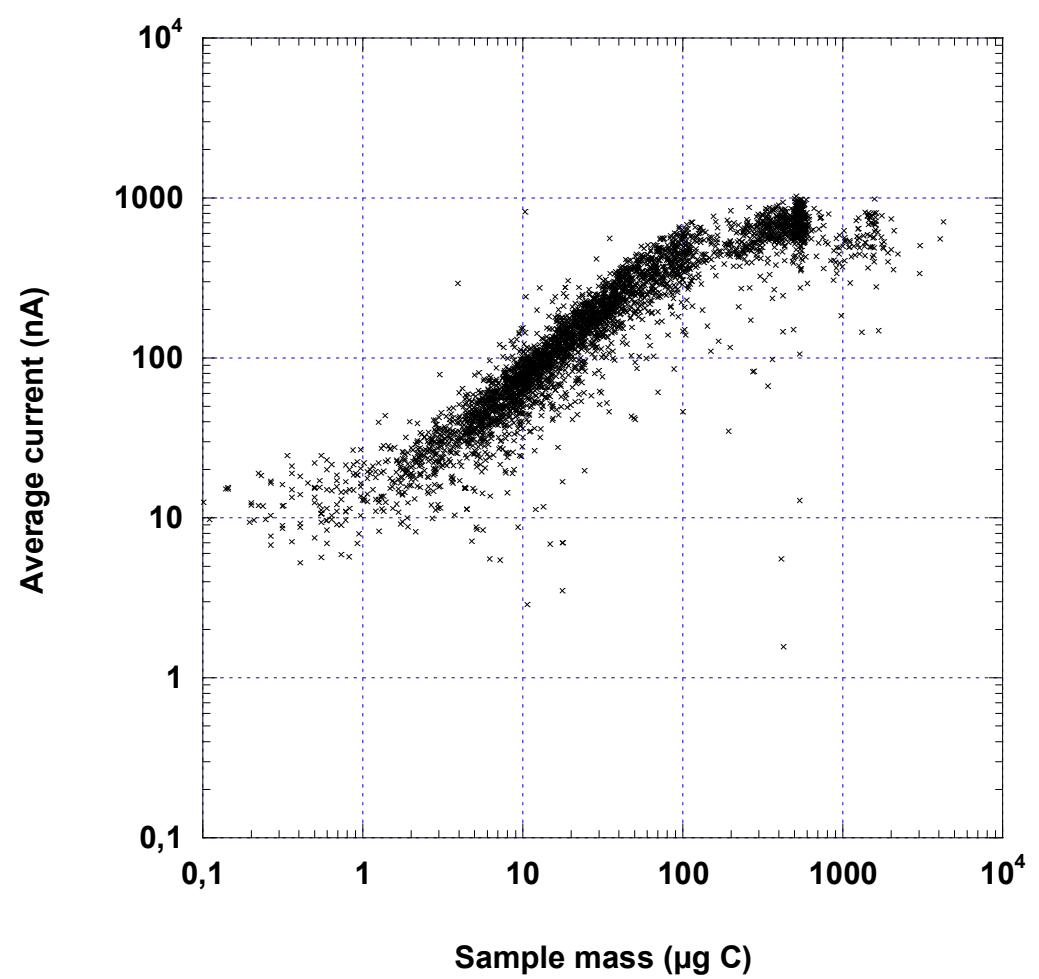

Figure 1 Measured secondary ion current of $12 \mathrm{MeV}{ }^{13} \mathrm{C}^{3+}$ as a function of the mass of the samples for 3643 samples prepared using the USS method. The current values are averaged over the first $5 \mathrm{~min}$. No data have been excluded. The plot is shown on a log-log scale.

Samples are typically analyzed for a total of $20 \mathrm{~min}(4 \times 5$ min periods $)$ during which time the secondary ion current decreases to a fraction of its original value. We have measured the amount of 


\section{Salehpour et al.}

sample left after such measurements by recombusting the remaining carbon and measuring the $\mathrm{CO}_{2}$ pressure using a calibrated volume and a standard pressure transducer). Typically, over half of the sample is left within the cathode as the cesium beam does not fully cover the whole sample volume. Consequently, it would be analytically beneficial to have a higher current during the measurement period.

The total integrated current has been shown by others (Santos et al. 2007) to increase with the amount of iron catalyst up to $4-5 \mathrm{mg}$. This led to a more sustainable secondary ion current from the sample during the measurement, compared to an initially higher current followed by a fast decrease for samples using smaller catalyst amounts. We have tried this at our laboratory but have not been able to observe the same improvements over smaller iron catalyst amounts. However, it should be noted that we use the zinc reduction method, whereas Santos et al. use the hydrogen reduction method, with a different chemistry and graphitization temperatures.

One possible method to increase the secondary current would be to change the ion source geometry (Middleton 1989; Southon et al. 2007) in order to increase the ionization efficiency and ion transmission over the sample surface. It has been reported that changing the sample surface geometry within the ion source can greatly enhance the secondary ion current for small samples (Yokoyama et al. 2010). Specifically, it was shown that by increasing the distance between the cathode surface and the graphite surface (cathode depth) by using a different mechanical press, the secondary ion current could be increased by a factor of 4 . The explanation that was proposed was that the increased cesium-induced plasma plume volume over the sample surface enhanced the probability of collision and hence ionization.

We have performed similar measurements, where samples with a cathode depth of $0.5 \mathrm{~mm}$ (standard) were compared to samples with cathode depth of $1.5 \mathrm{~mm}$. A total of 28 samples were prepared with masses in the range of about $1-100 \mu \mathrm{g} \mathrm{C}$ and analyzed with AMS. The quantity of interest is the secondary ion enhancement factor, i.e. the ratio $K$, of the average secondary ${ }^{13} \mathrm{C}$ ions originating from sample with cathode depths of 1.5 to that of standard samples $(0.5 \mathrm{~mm})$ of the same mass. Figure 2 shows the measured $K$ values as a function of the mass of the sample.

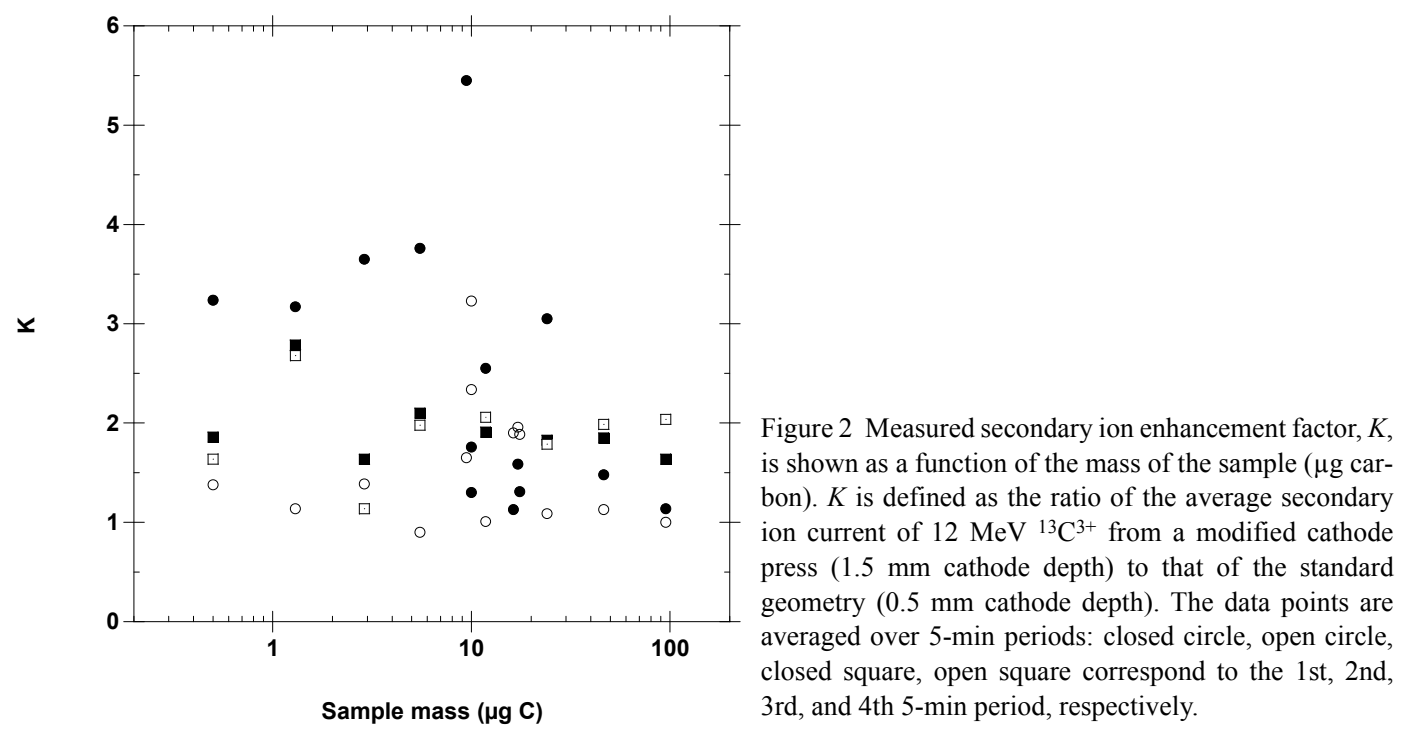




\section{Life Science Applications Utilizing ${ }^{14} \mathrm{C}$ Tracing}

Even though high $K$ values similar to Yokoyama et al.'s (2010) data have been observed for some samples, it is noted that the data points are clustered around a value of about 2. Nevertheless, this is a significant increase in secondary ion current. We have seen no detrimental effects on the pM values. Based on this encouraging data, we will proceed with more tests to find the optimized cathode depth for our ion source.

Another important issue is the accuracy of the ultra-small sample measurement. As previously mentioned, the measured isotopic ratio depends on the mass of the sample, which needs to be corrected for. Figure 3 shows the uncorrected isotopic ratio against the sample mass for 360 oxalic acid II samples collected during 70 consecutive AMS experiments, over a period of about $1 \mathrm{yr}$. No data points have been excluded in order to display the total variation and scatter. In accordance with our previous measurements (Salehpour et al. 2013), the pM mass dependence is weak down to $\sim 10 \mu \mathrm{g} \mathrm{C}$. As an example, a 10- $\mu \mathrm{g} \mathrm{C}$ sample has typically a few percent lower $\mathrm{pMC}$ value compared to a mg sample. The mass dependence is due to the carbon background and can be corrected for as described in Salehpour et al. (2013). The background carbon originating from ${ }^{14} \mathrm{C}$-free origins (dead carbon) and carbon from the laboratory atmosphere (Modern carbon) were determined as follows: Two series of dead carbon samples and modern samples at various masses were prepared and measured with AMS. Two methodologies were used to extract the average mass of the stray carbon: 1) The background carbon consisting of 2 components: Modern and dead carbon (Santos 2007) with values corresponding to $0.27 \pm 0.13 \mu \mathrm{g} \mathrm{C}$ for Modern carbon and $0.13 \pm 0.1 \mu \mathrm{g} \mathrm{C}$ for the dead carbon component. 2) Alternatively, an average value can be extracted for all the various carbon background contributions (Hua et al. 2004), giving a value of $0.36 \pm 0.11 \mu \mathrm{g} \mathrm{C}$ at $71 \mathrm{pMC}$.

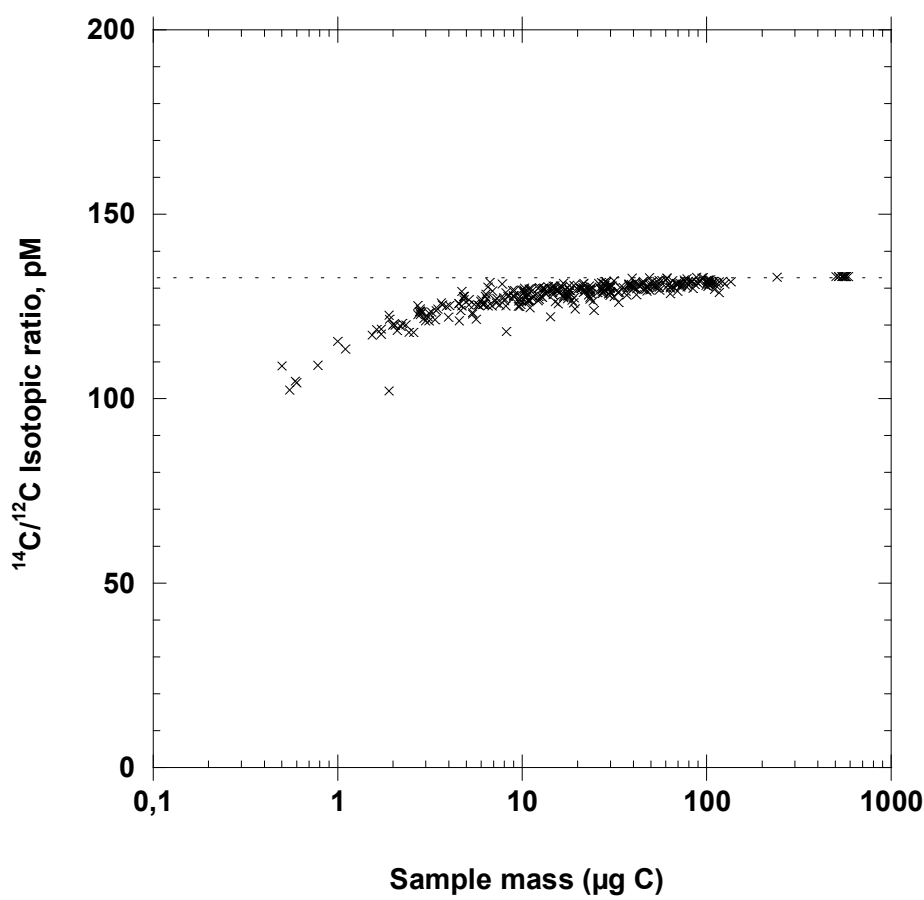

Figure 3 Measured ${ }^{14} \mathrm{C} /{ }^{12} \mathrm{C}$ ratio $(\mathrm{pM})$ as a function of the mass of Oxalic acid II standards at different masses. The data was recorded over a period extending more than one year and covering 70 AMS experiments, in total including 360 samples. No data have been excluded. 


\section{Salehpour et al.}

Even though the data is consistent, as can be seen in Figure 3, some scatter exists from one experiment to another. This may originate from other phenomena such as fractionation effects during measurements of small samples, which could vary from sample to sample. Nevertheless, the major effect is the carbon background and consequently, carbon background correction is applied individually for every AMS experiment by measuring standard samples at varying masses, covering the mass range of the samples of interest. As the carbon background values have been determined (average value of $0.36 \pm 0.11 \mu \mathrm{g} \mathrm{C}$ at $71 \mathrm{pMC}$ using the methodology of Hua et al. 2004), a least-square fit is used to fit the data for OX-II standards in every run and to extract the corresponding background values as a means of fine-tuning the correction values.

\section{LIFE SCIENCE APPLICATIONS}

A range of AMS biomedical research activities are currently being pursued at our laboratory (Salehpour 2013). Some new data are presented below, followed by a brief review of the ongoing activities.

\section{Amyloid Protein Analysis}

Systemic amyloidoses, a group of potentially lethal diseases, were long considered a mystery. They manifest themselves in a variety of symptoms depending on which organs that are affected. The damaging mechanism is the formation of highly insoluble protein fibrils that may physically impair the function for an organ, often the heart or kidney. In addition, there are many conditions in which amyloid is only present in a single tissue or organ, e.g. the brain (Alzheimer's disease) and the pancreatic islets (type 2 diabetes). For a review, see Merlini and Westermark (2004).

There are over 30 known endogenous proteins that can undergo conformational structural changes leading to amyloid formation. The proteins fold, align, and subsequently form fibrils with a typical width of around $10 \mathrm{~nm}$. Such fibrils can grow to tens of percent of the total weight of the organ until total functional failure occurs. Certain specific protein fibrils or their misfolded precursors are, in addition, toxic.

Like formation of infectious prions in spongioform encephalopathies (a known example being "mad cow disease"), development of amyloid fibrils is a nucleation-dependent process. The first step, formation of a nucleus for amyloid fibrils, is energetically unfavorable. On the other hand, elongation into mature fibrils is faster but depends on sufficient concentration of protein and on possible concomitant degradation as well as on other, yet unknown mechanisms in amyloidogenesis (Luheshi and Dobson 2009).

One key question in the field is the timespan over which the deposits are formed. In some cases, such as Alzheimer's disease, it is suspected that the process starts before the age of 30. One publication has addressed the bomb-peak dating of Alzheimer's plaques (Lovell et al. 2002) although no clear conclusions regarding the age of the plaque could be made from the study. We have access to samples from deceased individuals due to various amyloidosis diseases at the Rudbeck Laboratory at Uppsala University. In this study, we have included 3 different forms of systemic amyloidosis: AA amyloidosis ( 1 case) associated with chronic inflammatory processes, in this case rheumatoid arthritis; AL (immunoglobulin light chain) amyloidosis (4 cases), associated with plasma cell dyscrasia; and ATTR (wild type transthyretin) amyloidosis ( 3 cases), associated with aging.

Postmortem samples of the heart or spleen were processed as follows. The amyloid material is thoroughly homogenized repeatedly in $0.15 \mathrm{M}$ sodium chloride solution followed by centrifugation after which the supernatant is discarded. This procedure is repeated until soluble components have been 


\section{Life Science Applications Utilizing ${ }^{14} \mathrm{C}$ Tracing}

removed. After homogenization in distilled water and centrifugation, the pellet material is lyophilized. This amyloid fibril concentrate is then dissolved in 6M guanidine HCL and undergoing size-exclusion gel filtration in 5M guanidine HCL. The purification process has been described elsewhere (Westermark and Westermark 2005). The fraction containing the amyloid protein of interest is then dialyzed using distilled water. Samples are then lyophilized and stored. The samples finally undergo ${ }^{14} \mathrm{C}$ AMS analysis where the average formation age of the protein is extracted using the bomb-peak analysis. Figure 4 shows the principle behind the extraction of the average age of the amyloid protein formation time. The Levin and Kromer (2004) data set (CALIBomb) for the Northern Hemisphere (bomb peak) complemented with tree-ring data (Stuiver and Quay 1981) are plotted as a function of the calendar year. Superimposed are the measured $\Delta{ }^{14} \mathrm{C}$ values for 4 postmortem samples from individuals who died as a result of amyloidosis of internal organs. In the same graph, the year of death is also shown with a vertical dotted line. The difference between these 2 values is the average formation time of the proteins. Table 1 contains the list of measured samples.

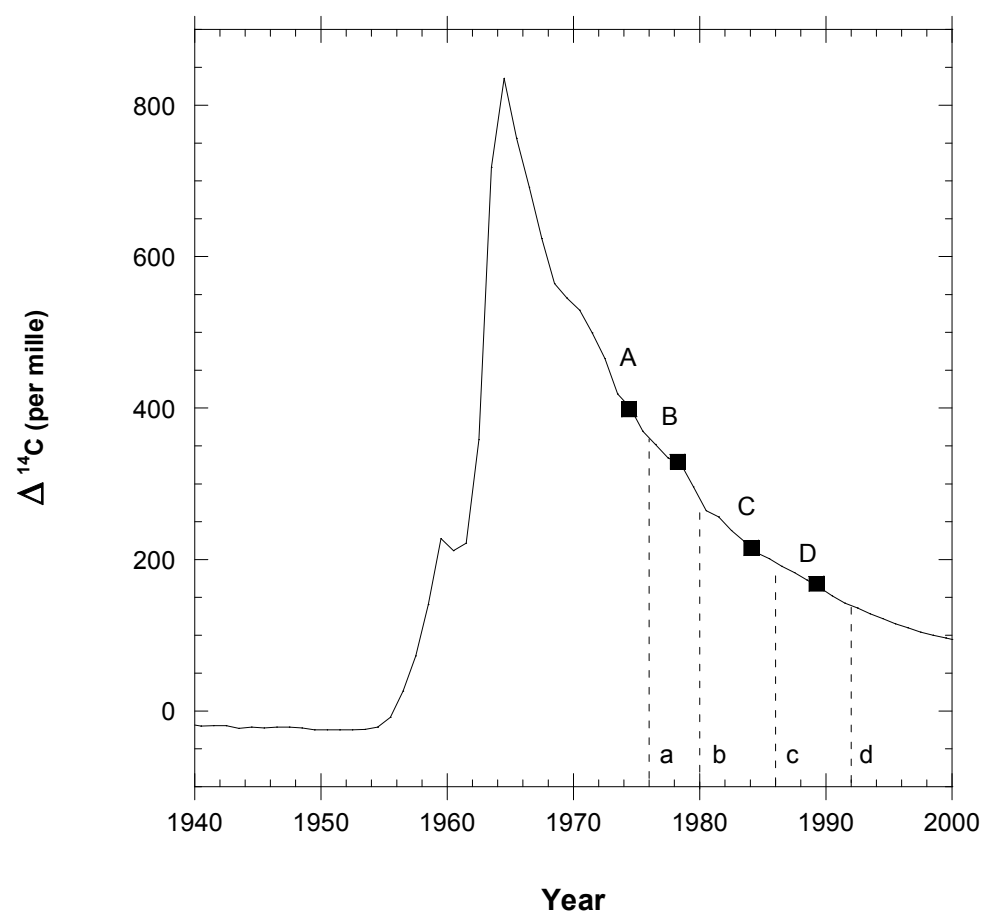

Figure 4 The bomb peak, based on the Levin and Kromer (2004) data, where $\Delta^{14} \mathrm{C}$ is plotted as a function of the calendar year. Measurement for 4 postmortem purified amyloid protein samples (A-D) in solid squares are superimposed on the bomb peak.

The corresponding year of death is also shown as a dotted line (a-d).

It is noted from the data in Table 1 that in spite of the variations in the year of birth and year of death, the associated amyloid proteins have consistently an average formation age that is within a few years from the date of death. This indicates that amyloidosis takes place within a few years prior to death rather than a slow mechanism taking decades. This information could be of interest to the elucidation of the mechanism behind amyloidogenesis and is consistent with a nucleation-dependent mechanism. It is particularly interesting to note that deposits in the age-dependent form of senile systemic amyloidosis, where wild-type transthyretin forms amyloid in the heart, is also of recent date. 


\section{Salehpour et al.}

Table 1 The list of analyzed amyloid samples, showing the Individual ID, the postmortem sample organ, the type of amyloid fibril protein, year of birth and death. Also shown are the $\delta^{13} \mathrm{C}$ and $\Delta^{14} \mathrm{C}$ measured values using stable isotope ratio mass spectrometry and AMS, respectively. The measured AMS values are cross-referenced in CALIBomb for the average formation date. The average formation time of the protein fibrils is then calculated in years. Protein types are AA = Serum AA (Apo); AL = Immunoglobulin light chain; and TTR = Transthyretin.

\begin{tabular}{llllllllll}
\hline Individual ID & Organ & Protein & $\begin{array}{l}\text { Year of } \\
\text { birth }\end{array}$ & $\begin{array}{l}\text { Year of } \\
\text { death }\end{array}$ & $\begin{array}{l}\delta^{13} \mathrm{C} \\
(\%)\end{array}$ & $\begin{array}{l}\Delta^{14} \mathrm{C} \\
(\%)\end{array}$ & $\begin{array}{l}\text { AMS error } \\
(1 \sigma)\end{array}$ & $\begin{array}{l}\text { Formation } \\
\text { date }\end{array}$ & $\begin{array}{l}\text { Formation } \\
\text { time }(\mathrm{yr})\end{array}$ \\
\hline $44447-896$ & Spleen & AA & 1911 & 1981 & -24.3 & 250.6 & 3.8 & 1981.2 & -0.2 \\
$44448 \mathrm{Ua} 600$ & Heart & AL & 1933 & 1991 & -23.2 & 148.6 & 3.9 & 1990.1 & 0.8 \\
$44449-700$ & Spleen & AL & 1914 & 1976 & -21.9 & 385.6 & 4.3 & 1974.7 & 1.3 \\
$44449: \mathrm{x}-700$ & Spleen & AL & 1914 & 1976 & -21.8 & 398.0 & 4.9 & 1974.2 & 1.8 \\
$44450-\mathrm{Hj}$ & Heart & TTR WT & 1900 & 1974 & -23.3 & 408.2 & 4.3 & 1973.8 & 0.2 \\
$44451-109$ & Spleen & AL & 1921 & 1986 & -24.3 & 213.7 & 3.8 & 1983.8 & 2.2 \\
$44452-272$ & Heart & TTR WT & 1891 & 1980 & -24.2 & 323.6 & 3.9 & 1977.9 & 2.1 \\
$44453-210$ & Heart & AL & 1926 & 1992 & -23.0 & 159.6 & 4.0 & 1989.1 & 2.8 \\
$44454-34$ & Heart & TTR WT & 1892 & 1984 & -23.3 & 239.7 & 4.2 & 1982.1 & 1.9 \\
\hline
\end{tabular}

\section{SUMMARY AND CONCLUSIONS}

A variety of ${ }^{14} \mathrm{C}$ life science research activities are being pursued at Uppsala University, including drug development studies and human cell regeneration rate measurements. Details of the ultra-small sample preparation method for $\mu \mathrm{g}$-size samples are outlined and new data is presented concerning the current dependence on the cathode geometry. Moreover, new results are presented on bombpeak dating of purified proteins from human postmortem amyloid deposits. Finally, we have noted a substantial increase in interest for various AMS applications within the biosciences during the last few years. A new AMS system has been ordered and will subsequently be in operation in the summer of 2014 to address this challenge.

\section{ACKNOWLEDGMENTS}

The Association against Familial Amyloidosis FAMY, FAMY Norrbotten and AMYL and the Swedish Research Council is gratefully acknowledged for the financial support (Linnaeus grant). The Swedish Research Council is gratefully acknowledged for the financial support. The effort for reading the manuscript and making valuable suggestions by Dr Anders Persson is much appreciated.

\section{REFERENCES}

Alkass K, Buchholz BA, Druid D, Spalding KL. 2009. Analysis of ${ }^{14} \mathrm{C}$ and ${ }^{13} \mathrm{C}$ in teeth provides precise birth dating and clues to geographical origin. Forensic Science 209(1-3):34-41.

Arner P, Bernard S, Salehpour M, Possnert G, Liebl J, Steier P, Buchholz BA, Eriksson M, Arner E, Hauner H, Skurk T, Rydén M, Frayn KN, Spalding KL. 2011. Dynamics of human adipose lipid turnover in health and metabolic disease. Nature 478(7367):110-3.

Bergmann O, Bhardwaj RD, Bernard S, Zdunek S, Barnabe-Heider F, Walsh S, Zupicich J, Buchholz B, Druid H, Jovinge S, Frisén J. 2009. Evidence for cardiomyocyte renewal in humans. Science 324(5923): 98-102.

Bernard S, Frisen J, Spalding KL. 2010. A mathematical model for the interpretation of nuclear bomb test derived ${ }^{14} \mathrm{C}$ incorporation in biological systems. Nuclear Instruments and Methods in Physics Research $B$ 268(7-8):1295-8.

Hägg S, Salehpour M, Noori P, Lundström J, Possnert G, Takolander R, Konrad P, Rosfors S, Ruusalepp A, Skogsberg J, Tegnér J, Björkegren J. 2011. Carotid plaque age is a feature of plaque stability inversely related to levels of plasma insulin. PLOS ONE 6(4): e18248.

Hua Q, Zoppi U, Williams AA, Smith AM. 2004. Smallmass AMS radiocarbon analysis at ANTARES. $\mathrm{Nu}$ clear Instruments and Methods in Physics Research B 223-224:284-92.

Lappin G, Garner C. 2003. Big physics, small doses: the 


\section{Life Science Applications Utilizing ${ }^{14} \mathrm{C}$ Tracing}

use of AMS and PET in human microdosing of development drugs. Nature Reviews, Drug Discovery 2(3): 223-40.

Levin I, Kromer B. 2004. The tropospheric ${ }^{14} \mathrm{CO}_{2}$ level in mid latitudes of the Northern Hemisphere. Radiocarbon 46(3):1261-72.

Lovell MA, Robertson JD, Buchholz BA, Xie C, Markesbery WR. 2002. Use of bomb-pulse carbon-14 to age senile plaques and neurofibrillary tangles in the Alzheimer's disease. Neurobiology of Aging 23(2): 179-186.

Luheshi LM, Dobson CM. 2009. Bridging the gap: from protein misfolding to protein misfolding diseases. FEBS Letters 583(16):2581-6.

Merlini G, Westermark P. 2004. The systemic amyloidoses: clearer understanding of the molecular mechanisms offers hope for more effective therapies. Journal of Internal Medicine 255(2):159-78.

Middleton R. 1989. A Negative Ion Cookbook. Department of Physics, University of Pennsylvania, Pennsylvania 19104, USA. Revised February 1990.

Sadiq M, Salehpour M, Forsgård N, Possnert G, Hammarlund-Udenaes M. 2011. Morphine brain pharmacokinetics at very low concentrations studied with accelerator mass spectrometry and liquid chromatography-tandem mass spectrometry. Drug Metabolism and Disposition 39(2):174-9.

Salehpour M, Possnert G, Bryhni H. 2008. Subattomole sensitivity in biological accelerator mass spectrometry. Analytical Chemistry 80(10):3515-21.

Salehpour M, Forsgard N, Possnert G. 2008. Accelerator mass spectrometry of small biological samples. Rapid Communications in Mass Spectrometry 22(23):392834.

Salehpour M, Forsgard N, Possnert G. 2009. FemtoMolar measurements using accelerator mass spectrometry. Rapid Communications in Mass Spectrometry 23(5): 557-63.

Salehpour M, Håkansson K, Possnert G. 2013. Accelerator mass spectrometry of ultra-small samples with applications in the biosciences. Nuclear Instruments and Methods in Physics Research B 294:97-103.

Salehpour M, Håkansson K, Höglund U, Grahn-Westin A, Nilsson S, Márquez M, Possnert G, Holmberg AR. 2011. Application of accelerator mass spectrometry to macromolecules: preclinical pharmacokinetic studies on a polybisphosphonate. Rapid Communications in
Mass Spectrometry 25(17):2453-8.

Santos GM, Southon JR, Griffin S, Beaupré SR, Druffel ERM. 2007. Ultra small-mass ${ }^{14} \mathrm{C}$-AMS sample preparation and analysis at the KCCAMS Facility. Nuclear Instruments and Methods in Physics Research B 259(1):293-302.

Spalding KL, Buchholz BA, Bergman LE, Druid H, Frisén J. 2005. Forensics: age written in teeth by nuclear tests. Nature 437(7057):333-4.

Southon J, Santos G, Han B. 2007. Cs feed test and emittance measurements on a modified MC-SNICS ion source for radiocarbon AMS. Radiocarbon 49(2): 301-6.

Spalding KL, Bergmann O, Alkass K, Bernard S, Salehpour M, Huttner HB, Boström E, Westerlund I, Vial C, Buchholz BA, Possnert P, Mash DX, Druid H, Frisen J. 2013. Dynamics of hippocampal neurogenesis in adult humans. Cell 153(6):1219-27.

Spalding KL, Arner E, Westermark PO, Bernard S, Buchholz BA, Bergmanm O, Blomqvist L, Hoffstedt J, Näslund E, Britton T, Concha H, Hassan M, Rydén M, Frisén J, Arner P. 2008. Dynamics of fat cell turnover in humans. Nature 453(7196): 783-7.

Stuiver M, Quay PD. 1981. Atmospheric ${ }^{14} \mathrm{C}$ changes resulting from fossil fuel $\mathrm{CO}_{2}$ release and cosmic ray flux variability. Earth and Planetary Science Letters 53(3):349-63.

Synal H-A, Stocker M, Suter M. 2007. MICADAS: a new compact radiocarbon AMS system. Nuclear Instruments and Methods in Physics Research B 259(1): $7-13$.

Turteltaub KW, Felton JS, Gledhill BL, Vogel JS, Southon JR, Caffee MW, Finkel RC, Nelson DE, Proctor ID, Davis JC. 1990. Accelerator mass spectrometry in biomedical dosimetry: relationship between low-level exposure and covalent binding of heterocyclic amine carcinogens to DNA. Proceedings of the National Academy of Sciences of the USA 87(14):5288-92.

Yokoyama Y, Koizumi M, Matzusaki H, Miyairi Y. 2010. Developing ultra small-scale radiocarbon sample measurement at the University of Tokyo. Radiocarbon 52(2-3):310-8.

Westermark GT, Westermark P. 2005. Purification of amyloid protein AA subspecies from amyloid-rich human tissues. Methods in Molecular Biology 299:24354. 